DE

M E D I C I N A

T R O P I C A L

$\mathrm{DE}$

SÃO PAULO

JOURNAL OF THE SÃO PAULO INSTITUTE OF TROPICAL MEDICINE

${ }^{1}$ Universidade Federal de Minas Gerais, Instituto de Ciências Biológicas, Departamento de Parasitologia, Belo Horizonte, Minas Gerais, Brazil

'Universidade Federal do Maranhão, Centro de Ciências Biológicas e da Saúde, Departamento de Patologia, São Luís, Maranhão, Brazil

${ }^{3}$ Universidade Estadual do Maranhão, Departamento de Química e Biologia, Laboratório de Parasitologia Humana, São Luís, Maranhão, Brazil

${ }^{4}$ Instituto Federal de Educação, Ciência e Tecnologia do Maranhão, Departamento de Educação, São Raimundo das Mangabeiras, Maranhão, Brazil

Correspondence to: Guilherme Silva Miranda Instituto Federal de Educação, Ciência e Tecnologia do Maranhão, Departamento de Educação, Rodovia BR-230, Km 319, Zona Rural, CEP 65840-000, São Raimundo das Mangabeiras, MA, Brazil

Tel: +5598 98814-6149

E-mail: mirandagsbio@gmail.com

Received: 15 April 2020

Accepted: 13 July 2020

\section{Effectiveness of a handmade shell-based substrate for the breeding of Biomphalaria glabrata under laboratory conditions}

\author{
João Gustavo Mendes Rodrigues ${ }^{\circledR 1}$, Maria Gabriela Sampaio Lira ${ }^{\circledR 2}$, \\ Ranielly Araújo Nogueira ${ }^{\circledR 2}$, Gleycka Cristine Carvalho Gomes ${ }^{2}$, Irlla Correia \\ Lima Licá2 , Davi Viegas-Melo ${ }^{3}$, Andrea Teles-Reis ${ }^{3}$, Guilherme Silva \\ Miranda ${ }^{1,4}$, Nêuton Silva-Souza ${ }^{3}$
}

\section{ABSTRACT}

Efficient snail production is essential for the proper maintenance of the Schistosoma mansoni life cycle in the laboratory. In order to improve the breeding of Biomphalaria glabrata under laboratory conditions, this study aimed to demonstrate the effectiveness of a handmade shellbased substrate on the physiological performance of $B$. glabrata. The shells used to make the substrate were cleaned, sterilized and macerated until a powder was obtained (yield of $92.3 \%$ ). B. glabrata specimens were randomly assigned to three treatment groups: negative control group (NCG) exposed to a clay-only substrate; a positive control group (PCG) containing clay, oyster flour and calcium carbonate; and the test group (TG) with the shell-based substrate and clay. B. glabrata bred in the test group showed improved growth, sexual maturity, fertility, mortality rate, and shell morphology when compared to the NCG, and similar to the PCG. Therefore, the shell-based substrate proved to be efficient and has a low cost for the breeding of B. glabrata.

KEYWORDS: Calcium carbonate. Shell-based substrate. Biomphalaria. Schistosomiasis. Mollusk breeding.

\section{INTRODUCTION}

Mollusks of the genus Biomphalaria act as intermediate hosts for the parasite Schistosoma mansoni, the etiological agent of the infectious and parasitic disease known as schistosomiasis ${ }^{1,2}$. Schistosomiasis is one of the most neglected tropical disease (NTDs) of significant medical importance, and is responsible for high levels of morbidity and mortality in affected individuals across different continents of the world ${ }^{3}$. Globally, it is estimated that the disease affects over 200-250 million people in 78 countries, most of them located in Africa, Latin America, the Middle East and Southeast Asia ${ }^{4,5}$. In Brazil, B. glabrata is the most important vector in the epidemiology of schistosomiasis owing to its high susceptibility to the parasite, in addition to its wide distribution ${ }^{6,7}$.

Currently, several research centers maintain the S. mansoni life cycle in their laboratories using experimental models of vertebrates (usually hamsters and mice) and invertebrates (mollusks of the genus Biomphalaria from different species and strains) in order to discover new mechanisms involved in the parasite-host interaction, screening of new drugs, immuno-physiological factors involved in the severity of the disease, and new diagnostic tools ${ }^{8}$. For this purpose, it is necessary that the intermediate 
hosts of S. mansoni, the mollusks, have favorable conditions for their development. Therefore, it is suggested that they should be properly maintained in glass aquariums containing dechlorinated water, supplied with an appropriate substrate layer (composed of clay, calcium carbonate and oyster flour), and food of plant origin, such as lettuce (Lactuca sativa L.) ${ }^{9}$.

Calcium carbonate, an essential component of the substrate needed for the effective breeding of B. glabrata, has been described as a limiting factor in the distribution and survival of mollusks in the environment, because it is necessary for muscle contraction, embryonic development, growth, immune responses and is also important in shell formation and strengthening ${ }^{10,11}$. Despite its great importance, it is the most expensive constituent and it is hardly available when researchers intend to produce a standardized substrate according to the recommendation of the Brazilian Ministry of Health, because, in general, the main commercial sources available are from oyster shells (sold only in specialized stores) or made in compounding pharmacies. Thus, it is necessary to investigate more accessible alternative sources of calcium carbonate with low cost that can be used for the effective breeding of B. glabrata in the laboratory.

Alternatively, the shell of Biomphalaria spp. which consists of $95 \%$ to $99 \%$ of calcium carbonate can be employed as a rich source of calcium in the production of the substrate used for breeding mollusks; the shell is characterized by a rigid external structure that plays the role of supporting and protecting the soft and delicate parts of the species against predators ${ }^{12,13}$. Thus, the shell of mollusks that would have been discarded can be reused to provide the calcium supply in the form of calcium carbonate in the substrate needed for their breeding.

The aim of this study was to develop a substrate with the same efficiency, low cost, and that is more accessible compared to the standardized substrate provided by the Brazilian Ministry of Health, for the breeding of B. glabrata under laboratory conditions.

\section{MATERIAL AND METHODS}

\section{Obtaining the macerate of $B$. glabrata shells}

The B. glabrata shells used in the study were obtained from the collection of the Laboratory of Human Parasitology at the State University of Maranhao (UEMA). A total of 1,000 shells (18 to $22 \mathrm{~mm}$ ) weighing 315.8 grams were used. The shells were sterilized by immersion in distilled water and neutral liquid soap for $24 \mathrm{~h}$, washed with running water, dried in an oven at $37^{\circ} \mathrm{C}$ for $24 \mathrm{~h}$, and then macerated using a porcelain gral and pistil to obtain the shell powder (approximately $92.3 \%$ of the initial weight), which was stored in vacuum tubes at $28{ }^{\circ} \mathrm{C}$ for subsequent use.

\section{Production of substrates}

The standardized substrate of the Brazilian Ministry of Health ${ }^{14}$, is made with sieved clay (10 parts), oyster flour ( 2 parts), and calcium carbonate (1.5 parts). Thus, 1,000 grams of the standardized substrate are made up of 740 grams of sieved clay, 145 grams of oyster flour and 115 grams of calcium carbonate.

In our experiment, sieved clay and macerated shells were used only in the production of the handmade shell-based substrate, and the mix was prepared with 10 parts of clay and 3.5 parts of macerated shell according to the standardized proportion recommended by the Brazilian Ministry of Health ${ }^{14}$. Thus, 1,000 grams of shell-based substrate are made up of 740 grams of sieved clay and 260 grams of macerated shells.

The species of mollusks used for the study was B. glabrata (BH strain), and they were randomly assigned to three treatment groups; positive control groups PCG (standardized substrate), negative control group NCG (clay only), and test group TG (handmade shell-based substrate).

\section{Experimental design}

The study was carried out in glass aquariums $(50 \times 25 \times 25 \mathrm{~cm})$ with capacity of $25 \mathrm{~L}$ of water (dechlorinated and filtered), and 12 grams of the substrates: PCG, NCG, and TG were added to the various treatment aquariums, respectively. Cleaning of the experimental aquariums and the addition of new substrates to the various treatment groups took place every 15 days. Physical and chemical parameters of the water, such as temperature, dissolved oxygen and $\mathrm{pH}$ were evaluated using a multiparameter probe (Thermo Scientific Orion Star A326).

The snails were fed ad libitum with fresh lettuce leaves $(L$. sativa $\mathrm{L}$.), which were washed with dechlorinated water. The laboratory temperature was maintained between $25^{\circ} \mathrm{C}$ and $28^{\circ} \mathrm{C}$, and all the experiments were carried out in triplicates.

\section{Mollusk growth and sexual maturity}

The spawns obtained from B. glabrata bred on the standardized substrate were counted and the viability of the embryos was confirmed through observation under a stereomicroscope. A total of 100 spawns were used for the growth and sexual maturity experiment. The growth study was carried out according to the method of Oliveira-Filho et al. ${ }^{15}$, with modifications. Fifteen days after 
hatching, 10 mollusks were randomly selected per treatment group and the shell measurement was conducted with the aid of a stereoscopic microscope coupled to a digital camera and a computer system (NIS-Elements advanced research). The measurement was repeated at each seven-days interval for a duration of 155 days.

The time of the first spawning in the different experimental groups was recorded by observing the activities on the Styrofoam $\left(8 \mathrm{~cm}^{2}\right)$ placed in the different aquariums at each seven days interval for a duration of over 50 days.

\section{Mortality and fertility of B. glabrata}

The study was conducted in aquariums with 50 snails (5-6 mm) per experimental group. The number of dead mollusks was recorded every 15 days. Fertility studies were carried out on the mollusks according to the method by Mangal et al. ${ }^{16}$, with modifications. The same groups of experimental snails were used for the mortality and fertility studies. For the fertility study, three pieces of $8 \mathrm{~cm}^{2}$ Styrofoam were placed in the experimental aquariums, only the number of spawns and embryos deposited on them were counted every three days with the aid of a stereoscopic microscope for a duration of 120 days. The spawns outside that place were not counted but were removed from the aquarium during each cleaning. Styrofoam pieces were replaced at each count and the values of the number of spawns and embryos were normalized by the number of live snails.

\section{Morphological characterization of $B$. glabrata shells}

The snails used in the study of the previous parameters were also used for the morphological examination, they were macroscopically analyzed to check for the presence of morphological and color changes in their shells, according to the procedures preconized by the Brazilian Ministry of Health ${ }^{14}$.

\section{Statistical analysis}

A two-way ANOVA test was used for the analysis of data obtained from the study, and the Bonferroni test for multiple comparisons was used to compare significant means obtained from the different experimental groups. Mortality was assessed using the Kaplan-Meier curve, and the Log-Rank test. Probability values less than 0.05 were considered statistically significant.

\section{RESULTS}

During the 155 days of the study, results on the growth assessment from the mollusks indicated that the test and positive control groups showed higher growth rates, compared to the negative control group (Figure 1). At the end of the study, the mean snail size was: $18.2 \pm 0.68 \mathrm{~mm}$, $17.8 \pm 0.56 \mathrm{~mm}$, and $12.4 \pm 0.45 \mathrm{~mm}$ for the test group, positive control group, and negative control group, respectively.

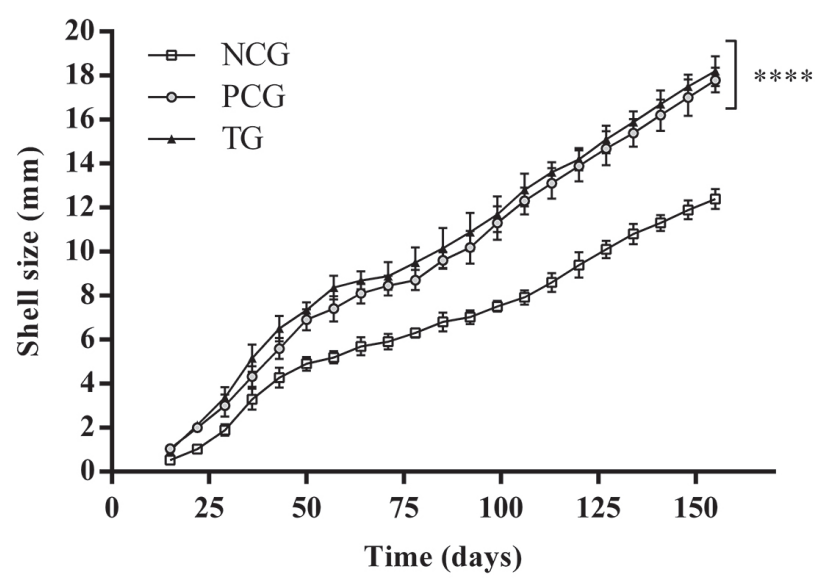

Figure 1 - Growth curve of B. glabrata bred using various experimental substrates: clay only in the negative control group (NCG), standardized substrate in the positive control group (PCG), and shell-based substrate in the test group (TG) for 155 days. A total of 100 B. glabrata per experimental group were used in the study. Statistically significant differences were obtained in comparisons with the negative control group.

Results from the assessment of sexual maturity showed that the mollusks in the test, and in the positive control groups performed oviposition earlier than mollusks in the negative group (Figure 2). The mean time (in days) of sexual maturity was: $34.9 \pm 0.52,33.3 \pm 0.3$, and $45 \pm 0.51$ for TG, PCG, and NCG, respectively.

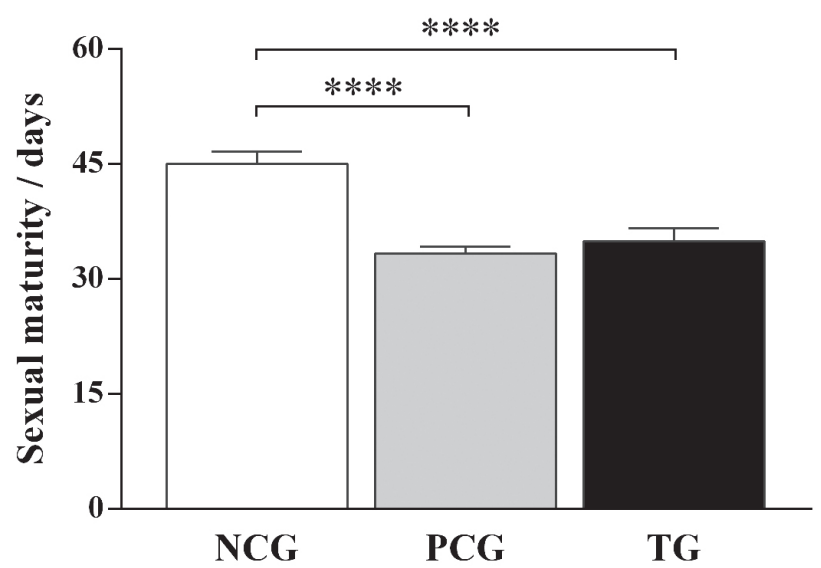

Figure 2 - Time of sexual maturity of $B$. glabrata bred using the various experimental substrates: clay only in the negative control group (NCG), standardized substrate in the positive control group (PCG), and shell-based substrate in the test group (TG). A total of 100 B. glabrata per experimental group were used in the study. Statistically significant differences were obtained in comparisons with the negative control group. 
(A)

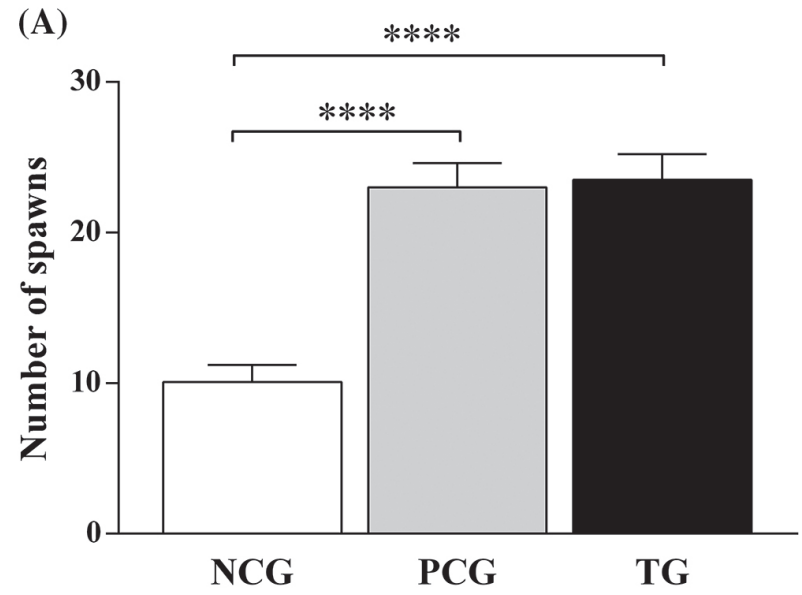

(B)

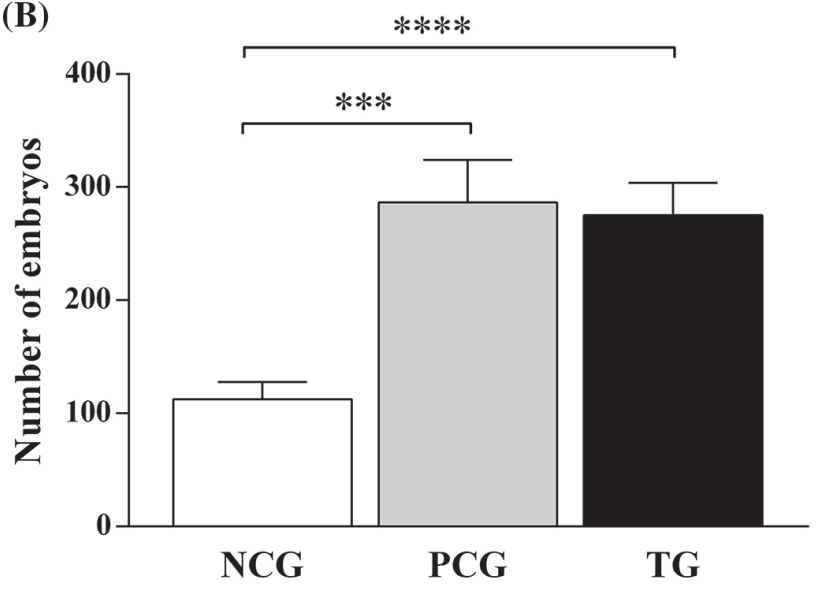

Figure 3 - Number of spawns (A) and embryos (B) of B. glabrata bred using the various experimental substrates: clay only in the negative control group (NCG), standardized substrate in the positive control group (PCG), and shell-based substrate in the test group (TG). A total of 50 snails per experimental group were used in the study. Statistically significant differences were obtained in comparisons with the negative control group.

During the 120 days of the study, the number of spawns (Figure 3A) and embryos (Figure 3B) in the test and positive-control groups was significantly higher than the number recorded in the negative control. The mean number of spawns and embryos was, respectively: $23.5 \pm 1.7$, and $275.0 \pm 28.7$ in the test group; $23.0 \pm 1.6$ and $286.4 \pm 37.6$ in the positive control group; $10.08 \pm 1.1$ and $112.6 \pm 15.1$ in the negative control group.

Results on the mortality assessment indicated that the test group (TG) and positive control group (PCG) had significantly lower number of dead snails compared to the negative control group (NCG), which recorded the death of all snails assigned to it by the end of the study (Figure 4). The number of deaths per analysis time point varied as follows: test group from 2 to 8 ; positive control from 3 to

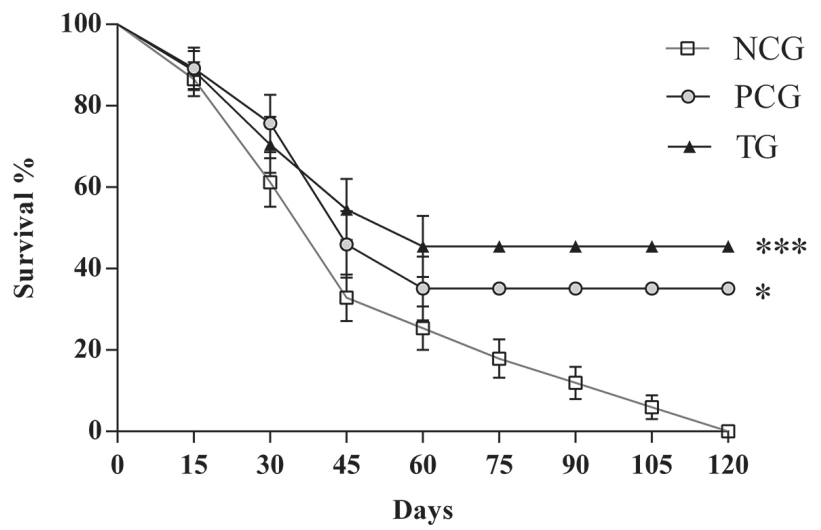

Figure 4 - Survival rate of $B$. glabrata bred using the various experimental substrates: clay only in the negative control group (NCG), standardized substrate in the positive control group (PCG), and shell-based substrate in the test group (TG) for 120 days. A total of 50 snails per experimental group were used in the study. Statistically significant differences were obtained in comparisons with the negative control group.
11 and negative control from 5 to 17. In all the experimental groups, the values of temperature $\left(21-25^{\circ} \mathrm{C}\right)$, dissolved oxygen $(2.9-3.6 \mathrm{mg} / \mathrm{mL})$ and $\mathrm{pH}(7.0-7.4)$ were within the normal range.

Morphologically, the shells of snails in the test group (Figure 5C), and positive control group (Figure 5B) ranged from light brown to dark brown in color, with fewer cracks/ fractures (yellow arrows) around their turns, in comparison with snails in the negative control group (Figure 5A), despite having similar shell coloration in respect to the TG, and the PCG had more cracks/fractures along the turns of their shells.

\section{DISCUSSION}

Mimicking optimal conditions in the laboratory for B. glabrata breeding has always been of interest to research centers, since these animals are needed on a large scale to maintain the $S$. mansoni life cycle, as well as other helminths of medical importance, such as Angiostrongylus ${ }^{17}$. Thus, the result of the present study showed that a simple shell-based substrate, made from a sustainable material (the shells of mollusks), can be a promising substrate to be used for the breeding of $B$. glabrata under laboratory conditions.

In general, results from the present study indicated that the handmade shell-based substrate resulted in improved survival and growth rate, shell strength, and reproductive performance (short time of sexual maturation and increase in the rate of oviposition), which is comparable to results obtained from snails bred using the standardized substrate recommended by the Brazilian Ministry of Health. Improvements of $B$. glabrata physiological performance have already been demonstrated by several researchers, 

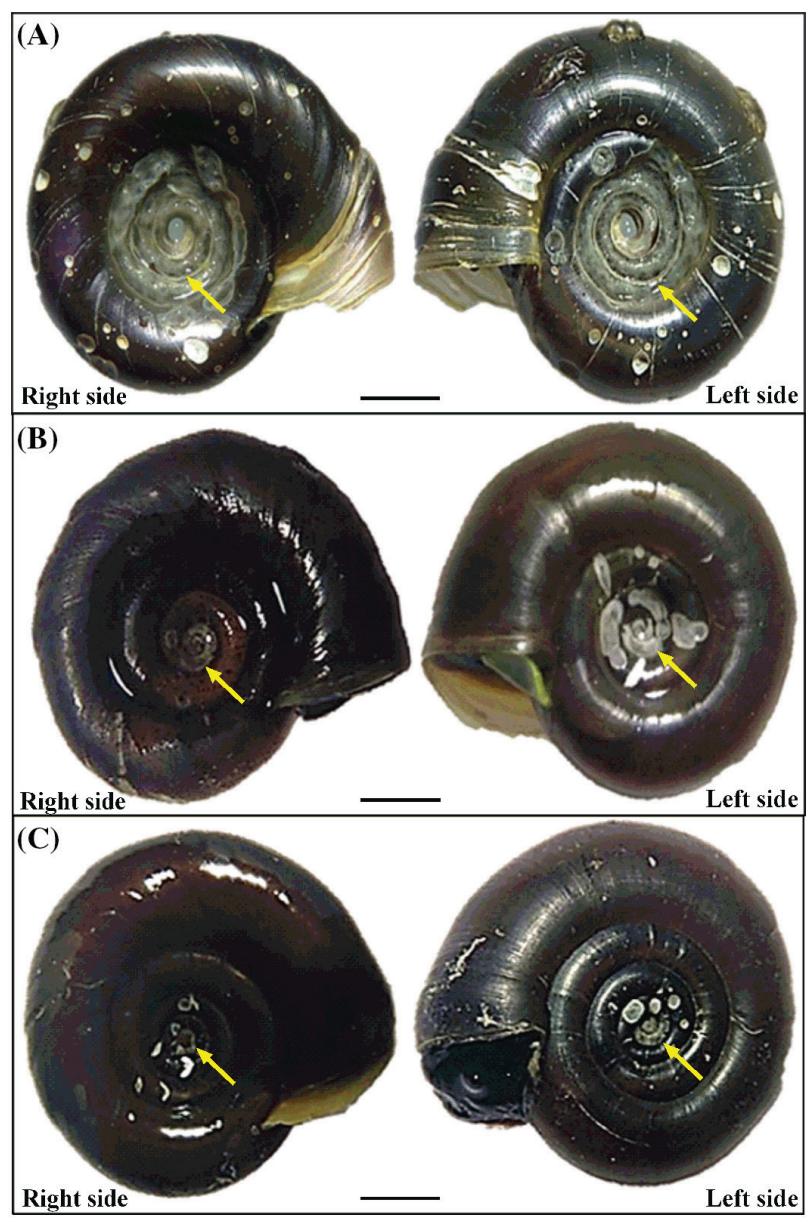

Figure 5 - Morphology of $B$. glabrata shells bred using the various experimental substrates: $(A)$ Negative control group - NCG (with clay only); (B) Positive control group - PCG (with the standardized substrate); (C) Test group - TG (with the shellbased substrate). The yellow arrows indicate cracks/fractures on the shells. Scale: $5 \mathrm{~mm}$.

under laboratory conditions, when the aquatic environment in which they are bred has the presence of optimal levels of bioavailable calcium ${ }^{10,12,18,19}$. This demonstrates that B. glabrata shells can be an effective and low cost alternative to the calcium carbonate supplementation for the breeding of these snails in the laboratory.

Some researchers have already described the use of calcium and sources in the first stages of life of B. glabrata. The developing embryos obtain calcium from the perivitelline liquid and the gelatinous matrix (internal tunic) of the ovigerous mass. However, after one week, the external environment becomes the most important source of calcium for these animals ${ }^{13}$. In their natural environment, some studies have shown that B. glabrata has a preference for calcium-rich environments ${ }^{20}$; calcium concentration below $20 \mathrm{mg} / \mathrm{L}$ affects negatively the breathing of mollusks and also decrease their motility ${ }^{21}$. Although the percentage of calcium carbonate in the shell-based substrate used in the present study was not evaluated, some studies indicated that the shell of the mollusks contain about $95 \%$ to $99 \%$ of calcium carbonate ${ }^{12,13}$; however, it is necessary to confirm this information in future studies for the better standardization and validation of shell-based substrates. Even so, due to the positive findings of the present study; improved biological and physiological parameters of B. glabrata bred on this shell-based substrate, it can be concluded that the calcium content of the shell-based substrate was sufficient for the proper breeding of snails under the test conditions.

In the current study, it was observed that the use of shells for the substrate production is a relatively cost-free and easy logistics process. This is because of the high reproductive capacity of B. glabrata when bred under optimum conditions in laboratory studies ${ }^{22}$, thus making them a high source of the raw material (shells) for the production of the substrate. In addition, encouraging the collection of these animals in the field for breeding purposes may promote an epidemiological control of schistosomiasis. Thus, the productive cycle of this shell-based substrate can be a self-sustainable, beneficial and profitable process on a large scale.

In summary, results from the present study indicated that the substrate composed of clay and macerated shells of $B$. glabrata can be used as a sustainable and an economically viable alternative for breeding $B$. glabrata under laboratory conditions, and can improve the result of researches that deal with $B$. glabrata. In addition, the use of shells from other mollusks to produce substrates requires further investigation.

\section{ACKNOWLEDGMENTS}

We thank the Universidade Estadual do Maranhão, for infrastructure and carrying out the experiments.

\section{AUTHORS' CONTRIBUTIONS}

Designed the study: GSM, JGMR and NSS; performed the experiments: JGMR, MGSL, RAN, GSM, GCCG, ICLL, DVM and ATR; analyzed the data: JGMR, GSM and NSS; wrote the paper: JGMR, GSM, MGSL, RAN, ICLL and DVM. All authors reviewed and approved the final version.

\section{CONFLICT OF INTERESTS}

The authors declare that they have no conflict of interests. 


\section{REFERENCES}

1. Scholte RG, Gosoniu L, Malone JB, Chammartin F, Utzinger J, Vounatsou P. Predictive risk mapping of schistosomiasis in Brazil using Bayesian geostatistical models. Acta Trop. 2014;132:57-63.

2. World Health Organization. Investing to overcome the global impact of neglected tropical diseases: third WHO report on neglected tropical diseases. Geneva: WHO; 2015. [cited 2020 Jul 14]. Available from: https://www.who.int/neglected_ diseases/9789241564861/en/

3. Hotez PJ, Kamath A. Neglected tropical diseases in sub-Saharan Africa: a review of their prevalence, distribution, and disease burden. PLoS Negl Trop Dis. 2009;3:e412.

4. Steinmann P, Keiser J, Bos R, Tanner M, Utzinger J. Schistosomiasis and water resources development: systematic review, metaanalysis, and estimates of people at risk. Lancet Infect Dis. 2006;6:411-25.

5. Naghavi M, Abajobir AA, Abbafati C, Abbas KM, Abd-Allah F, Abera SF, et al. Global, regional, and national under-5 mortality, adult mortality, age-specific mortality, and life expectancy, 1970-2016: a systematic analysis for the Global Burden of Disease Study 2016. Lancet. 2017;390:1151-210.

6. Souza CP, Cunha R, Andrade ZA. Development of Schistosoma mansoni in Biomphalaria tenagophila, Biomphalaria straminea and Biomphalaria glabrata. Rev Inst Med Trop Sao Paulo. 1995;37:201-6.

7. Carvalho OS, Coelho PM, Lenzi HL, organizadores. Schistosoma mansoni e esquistossomose: uma visão interdisciplinar. Rio de Janeiro: Fiocruz; 2008.

8. Brasil. Ministério da Saúde. Secretaria de Vigilância em Saúde. Coordenação-Geral de Desenvolvimento da Epidemiologia em Serviços. Guia de vigilância em saúde: volume único. $2^{\mathrm{a}}$ ed. Brasília: Ministério da Saúde; 2017. [cited 2020 Jul 14]. Available from: http://portalarquivos.saude.gov.br/images/ pdf/2017/outubro/06/Volume-Unico-2017.pdf

9. Malek EA. Snail hosts of schistosomiasis and other snailtransmitted diseases in tropical America: a manual. Washington, DC: PAHO; 1985.

10. Davies TW, Erasmus DA. An ultrastructural study of the effect of parasitism by larval Schistosoma mansoni on the calcium reserves of host, Biomphalaria glabrata. Cell Tissue Res. 1984;236:643-9.

11. Tunholi VM, Lustrino D, Tunholi-Alves VM, Mello-Silva CC, Maldonado Jr A, Rodrigues ML, et al. Changes in the reproductive biology of Biomphalara glabrata infected with different doses of Echinostoma paraensei miracidia. J Invertebr Pathol. 2011;106:192-5.
12. Marxen JC, Becker W, Finke D, Hasse B, Epple M. Early mineralization in Biomphalaria glabrata: microscopic and structural results. J Moll Stud. 2003;69:113-21.

13. Ebanks SC, O'Donnell MJ, Grosell M. Characterization of mechanisms for $\mathrm{Ca}^{2+}$ and $\mathrm{HCO}_{3}{ }^{-} / \mathrm{CO}_{3}{ }^{2-}$ acquisition for shell formation in embryos of the freshwater common pond snail Lymnaea stagnalis. J Exp Biol. 2010;213:4092-8.

14. Brasil. Ministério da Saúde. Secretaria de Vigilância em Saúde. Departamento de Vigilância Epidemiológica. Vigilância e controle de moluscos de importância epidemiológica. $2^{\mathrm{a}}$ ed. Brasília: Ministério da Saúde; 2008. [cited 2020 Jul 14]. Available from: https://www.saude.gov.br/images/pdf/2015/ agosto/14/vigilancia-controle-moluscos-import-epidemio-2ed. pdf

15. Oliveira-Filho EC, Sousa Filho J, Novais LA, Peternele WS, Azevedo RB, Grisolia CK. Effects of $\gamma-\mathrm{Fe}_{2} \mathrm{O}_{3}$ nanoparticles on the survival and reproduction of Biomphalaria glabrata (Say, 1818) and their elimination from this benthic aquatic snail. Environ Sci Pollut Res Int. 2016;23:18362-8.

16. Mangal TD, Paterson S, Fenton A. Effects of snail density on growth, reproduction and survival of Biomphalaria alexandrina exposed to Schistosoma mansoni. J Parasitol Res. 2010;2010:186792.

17. Guerino LR, Carvalho JF, Magalhães LA, Zanotti-Magalhães EM. Susceptibility of Biomphalaria glabrata submitted to concomitant infection with Angiostrongylus costaricensis and Schistosoma mansoni. Braz J Biol. 2017;77:451-8.

18. Thomas JD, Benjamin M, Lough A, Aram RH. The effects of calcium in the external environment on the growth and natality rates of Biomphalaria glabrata (Say). J Anim Ecol. 1974;43:839-60.

19. Magalhães AC, Pinheiro J, Mello-Silva CC. A mobilização do cálcio em Biomphalaria glabrata exposta a diferentes quantidades de carbonato de cálcio. Rev Patol Trop. 2011;40:46-55.

20. Silva PB, Barbosa CS, Pieri O, Travassos A, Florencio L. Aspectos físico-químicos e biológicos relacionados à ocorrência de Biomphalaria glabrata em focos litorâneos da esquistossomose em Pernambuco. Quim Nova. 2006;29:901-6.

21. Dalesman S, Braun MH, Lukowiak K. Low environmental calcium blocks long term memory formation in a pulmonate snail. Neurobiol Learn Mem. 2011;95:393-403.

22. Barbosa CS, Silva CB, Barbosa FS. Esquistossomose em Pernambuco: reprodução e expansão da endemia. Rev Saude Publica. 1996;30:609-16. 